\title{
Circunstâncias que envolvem o suicídio de pessoas idosas
}

\author{
Girliani Silva de Sousa ${ }^{(a)}$ \\ Raimunda Magalhães da Silva(b) \\ Ana Elisa Bastos Figueiredo(c) \\ Maria Cecília de Souza Minayo ${ }^{(d)}$ \\ Luiza Jane Eyre de Souza Vieira ${ }^{(e)}$
}

Sousa GS, Silva, RM, Figueiredo AEB, Minayo MCS, Vieira LJES. Circumstances surrounding the suicide of elderly people. Interface (Botucatu).

This text analyses experiences and family relationships that preceded the suicide of an elderly person. This was a qualitative study using the psychosocial autopsy method. The cases of 16 elderly people who committed suicide in three cities in northeastern Brazil between 2006 and 2009 were considered. From content analysis, two categories were elucidated: experiences that came before the suicide and enunciation of the suicide by the elderly person to family members. The prominent factors associated with the suicide were mood swings and expressions of depressive states, family conflicts permeated by financial problems and abusive use of alcohol and suicidal ideation through announcing the wish to finish life early. Wide-ranging viewpoints and reflective listening in relation to these elderly individuals become necessary among social workers, family members, friends and several sectors: specifically, managers and professionals of the healthcare sector who can create significant changes in the dynamics of the service.

Keywords: Elderly person. Suicide. Family dynamics.
O trabalho analisa experiências e relações familiares que antecederam o suicídio de idosos. Trata-se de pesquisa qualitativa, com método de autópsia psicossocial. Contempla casos de 16 idosos que cometeram suicídio entre 2006 a 2009 em três municípios do Nordeste Brasileiro. À luz da Análise de Conteúdo, elucidaram-se as categorias: experiências que antecederam o suicídio de pessoas idosas e enunciação do suicídio pelo idoso aos seus componentes familiares. Destacam-se os fatores associados ao suicídio: alterações de humor e expressões de estados depressivos, conflitos familiares permeados por dificuldades financeiras, e uso abusivo de álcool e ideação suicida por anunciação do desejo de antecipar seu fim. Tornamse necessários o olhar abrangente e o ouvir reflexivo sobre o idoso por parte dos agentes sociais, familiares, amigos e diversos setores, especificamente o setor saúde, gestores e profissionais que provoquem mudanças significativas na dinâmica do serviço.

Palavras-chave: Idoso. Suicídio. Dinâmica familiar.

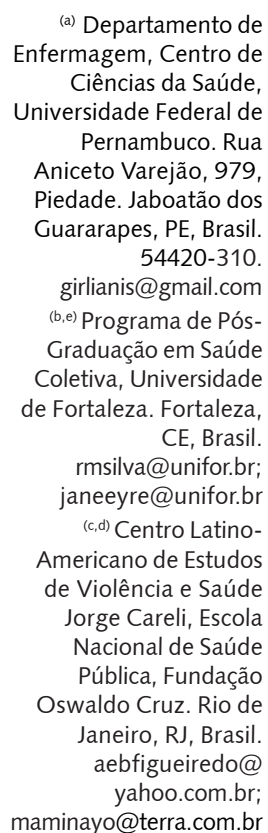




\section{Introdução}

O crescimento da população idosa é um dos fenômenos mais notórios em todo o mundo, trazendo consigo repercussões culturais, sociais e políticas ${ }^{1,2}$. O Brasil é um país que envelhece velozmente: a cada ano, seiscentos e cinquenta mil novos idosos são incorporados à população brasileira ${ }^{2}$. As projeções para o ano 2020 estimam 32 milhões, o que situará o Brasil na sexta posição mundial em número de idosos ${ }^{3}$.

Quando alcançam a terceira idade, é importante que as pessoas possam conviver melhor consigo mesmas e com os outros, integrando positivamente as limitações fisiológicas próprias do envelhecimento, as mudanças na sua visão de mundo e os modos de viver os inter-relacionamentos familiares e sociais, conforme preconiza a Organização Mundial de Saúde ${ }^{4}$. Com efeito, envelhecer é um processo e, nessa organização interna e externa, alguns idosos podem expressar dificuldades que se prolongam, cristalizam e podem evoluir para estados depressivos ou, mesmo, depressão.

A depressão, como transtorno mental, e outros agravos afetivos, ocasionam potenciais fragilidades e constituem significativos fatores de risco para o suicídio de idosos ${ }^{1,5,6}$, uma vez que interferem nos laços sociais e sua ruptura, sobretudo no caso de personalidades rígidas, ansiosas e obsessivas ${ }^{7}$.

O suicídio de idosos é um fenômeno estudado pela literatura internacional ${ }^{8}$ como grave problema de saúde pública ${ }^{4,8}$. Pesquisa realizada pelo Multicentre Study of Suicidal Behaviour (WHO/EURO) ${ }^{9}$, em 13 países europeus, mostra que as taxas médias de morte por autoviolência, entre pessoas de mais de 65 anos nessas sociedades, chega a 29.3/100.000. Nessa direção, novos trabalhos de aprofundamento do tema são necessários, quando contribuem para a elaboração de planos de ação voltados ao cuidado integral com o idoso ${ }^{10,11}$.

A complexidade do tema "suicídio de idosos" demanda uma abordagem qualitativa que possa fazer dialogar dados e informações epidemiológicas, com sociológicas, antropológicas e psicológicas ${ }^{12}$. Com origem nessa triangulação teórica, pretende-se a aproximação das histórias que os familiares contam sobre os dias anteriores ao suicídio de idosos do Nordeste brasileiro, analisando as histórias relatadas por seus familiares sobre o fato, quanto aos aspectos emocionais, físicos, psíquicos, sociais e culturais.

Durkheim ${ }^{13}$, que estudou o suicídio do ponto de vista da Sociologia, o define como "Todo caso de morte que resulta direta ou indiretamente de um ato, positivo ou negativo, realizado pela própria vítima que sabia que se produziria esse resultado". Para isso, elaborou um modelo sociológico que ressalta os padrões e regularidades do fenômeno. Em diálogo com esse autor referencial ou criticando seu marco teórico, estudiosos passaram a ressaltar os aspectos microssociais e subjetivos desse ato existencial ${ }^{14,15}$. Nessa linha de pensamento, compreende-se o ato suicida como decisão pessoal permeada pela interpretação dos aspectos psicossociais vivenciados pelo indivíduo. Cada sujeito está em interação intensa com os outros membros da família e com a sociedade. Por isso, deve-se considerar a série de fatores que vão se acumulando na biografia da pessoa, tornando seu sofrimento insuportável e culminando no suicídio ${ }^{16}$.

O suicídio é um ato consciente de autoaniquilamento, vivenciado por aquele em situação de vulnerabilidade, que o percebe como a melhor solução para escapar de uma dor psicológica insuportáve ${ }^{16}$. Neste ensejo, o suicídio resulta da intencionalidade do sujeito, mas é influenciado por fatores sociais e microssociais.

Desse modo, indaga-se: como estavam as relações familiares que circundavam esse idoso suicida? De que modo esse idoso se mostrava em sua condição física, emocional e psicológica nos dias que antecederam o ato suicida? As pessoas do convívio social desse idoso perceberam indícios de que ele estava desistindo da vida?

Nessa direção, este artigo faz uma inflexão específica sobre os momentos anteriores ao suicídio. $\bigcirc$ termo "momento" aqui é utilizado como uma representação vívida da memória dos familiares, sem necessariamente coincidir com o tempo cronológico.

$\mathrm{Na}$ interlocução das correntes sociológica e psicológica, que debatem o contexto social, bem como a internalização do sujeito, o texto reúne algumas reflexões diante do fenômeno, que assumem importância, sobremaneira, pelo envelhecimento populacional e o que isso significa para a sociedade. 


\section{Metodologia}

A investigação que dá origem a este artigo ocorreu nas cidades de Teresina (PI), Tauá (CE) e Fortaleza (CE), e se insere num projeto de âmbito nacional intitulado: "É possível prevenir a antecipação do fim? Suicídio de Idosos no Brasil e possibilidades de atuação do Setor Saúde". Entre os nove estados que compõem a região Nordeste do Brasil, em seis, incluindo Piauí e Ceará, em 2009, as taxas de suicídio na população masculina superaram 10/100.000 habitantes, índice considerado relevante na pesquisa nacional e elevado dentro dos parâmetros da $\mathrm{OMS}^{17}$.

Embora partisse de uma pesquisa de série histórica e de especificação dos municípios brasileiros ${ }^{17-19}$, outros estudos ${ }^{12,20}$ enfatizaram a abordagem qualitativa por meio de autópsias psicossociais - conceito já bastante estudado por Cavalcante e Minayo ${ }^{15}$. Essa abordagem metodológica faz uma reconstituição narrativa com suporte em um roteiro de referência, para entrevista com os familiares dos idosos sobre: a) caracterização social; b) retrato e modo de vida; c) avaliação da atmosfera do ato de suicídio; d) estado mental que antecedeu o suicídio; e) reflexão da família sobre o ato ${ }^{21}$.

Os procedimentos para localizar os familiares dos idosos que faleceram por suicídio ocorreram por: levantamento no Instituto Médico Legal (IML), contato com a Secretaria de Saúde do Estado do Ceará (SESA), com a Secretaria Municipal de Saúde de Tauá, e com a Estratégia Saúde da Família (ESF), que forneceram a listagem com as informações necessárias para localização das residências. A identificação dos casos foi feita segundo recomendações da literatura ${ }^{16}$, que expressa ser conveniente não estudar casos muito recentes (arbitrados até dois anos do fato ocorrido) e nem muito antigos (arbitraram-se cinco anos), buscando-se respeitar elementos emocionais das histórias, mas de forma o mais possível já elaborada no tempo.

Tendo em mãos a listagem dos casos, procedeu-se ao contato com os familiares por telefone, buscando agendar as entrevistas. Dez famílias de idosos que haviam falecido por suicídio não foram localizadas; duas se recusaram a ser entrevistadas, alegando não estarem preparadas emocionalmente para relatar o ocorrido; duas aceitaram participar, mas, no momento em que os pesquisadores compareceram na data e local agendado, recusaram, alegando os mesmos motivos descritos a respeito de outras recusas.

As entrevistas ocorreram no período de maio e junho de 2011. Inicialmente, começou-se o trabalho de maneira muito informal, criando-se um clima propício à conversa. Em seguida, foram fornecidas informações sobre a relevância desta pesquisa, bem como lidos os objetivos e o Termo de Consentimento Livre e Esclarecido (TCLE), propiciando, aos interlocutores, um ambiente de empatia, para que relatassem livremente suas recordações, pensamentos e sentimentos. Buscou-se respeitar os momentos fortes de emoção e choro. Em geral, os familiares agradeceram o fato de poderem falar do que havia acontecido sem serem julgados e, ao contrário, dentro de um momento compreensivo e acolhedor.

A maioria das entrevistas ocorreu ouvindo-se mais de um membro da família, no entanto, considerou-se que um informante-chave deveria assumir a reconstituição da história de vida do idoso que faleceu por suicídio e que os outros adicionassem elementos importantes para elucidar a compreensão do ato. O acervo das entrevistas compreendeu as histórias de 16 idosos, contadas por 42 familiares (viúva, ex-esposa, irmãos(ãs), filhos(as), sobrinha e netos) em ambiente escolhido por elas (varanda, salas, cozinha, galpão e restaurante). Todos os que aceitaram participar consentiram que a conversa fosse gravada e essas gravações duraram, em média, sessenta minutos.

Após a realização das entrevistas, os dados foram compilados e consolidados. Buscou-se organizar a história de cada idoso, em relação aos dias que antecederam o suicídio, e procedeu-se a síntese analítica do conjunto, dentro de alguns núcleos de sentido: mudanças de humor; conflitos familiares; depressão; rejeição de doenças crônicas; verbalização do desejo de morrer, e conformando duas categorias principais: (1) experiências que antecederam o suicídio do idoso, e (2) enunciação do suicídio, pelo idoso, aos seus familiares.

O projeto que originou este artigo foi aprovado pelo Comitê de Ética e Pesquisa da Fundação Oswaldo Cruz, e todos os informantes assinaram o Termo de Consentimento Livre e Esclarecido (TCLE). As recomendações desses instrumentos foram respeitadas. Os membros familiares que expressaram 
CIRCUNSTÂNCIAS QUE ENVOLVEM O SUICÍDIO ...

alterações emocionais mais fortes foram encaminhados e recomendados aos serviços de saúde considerados de referência.

\section{Resultados e discussão}

Após as informações dos familiares para reconstituição dos dias que antecederam o suicídio, julgouse relevante trazer a caracterização dos idosos, cujos casos são aqui analisados (Tabela 1).

Tabela 1. Caracterização dos idosos que faleceram por suicídio

\begin{tabular}{|c|c|c|c|c|c|}
\hline & \multirow{2}{*}{$\begin{array}{l}\text { Teresina } \\
\mathrm{N}\end{array}$} & \multirow{2}{*}{$\begin{array}{c}\text { Tauá } \\
\mathrm{N}\end{array}$} & \multirow{2}{*}{$\begin{array}{l}\text { Fortaleza } \\
\qquad \mathrm{N}\end{array}$} & \multicolumn{2}{|c|}{$(N=16)$} \\
\hline & & & & $\mathrm{N}$ & $\%$ \\
\hline \multicolumn{6}{|l|}{ Sexo } \\
\hline Masculino & 4 & 5 & 5 & 14 & 87,5 \\
\hline Feminino & 2 & - & - & 2 & 12,5 \\
\hline Subtotal & 6 & 5 & 5 & 16 & 100 \\
\hline \multicolumn{6}{|l|}{ Estado Civil } \\
\hline Solteiro (a) & 1 & - & - & 1 & 6,2 \\
\hline (Re) casado ou em união estável & 2 & 5 & 4 & 11 & 68,7 \\
\hline Divorciado ou separado & 2 & - & 1 & 3 & 18,7 \\
\hline Viúvo (a) & 1 & - & - & 1 & 6,2 \\
\hline Subtotal & 6 & 5 & 5 & 16 & 100 \\
\hline \multicolumn{6}{|l|}{ Escolaridade } \\
\hline Analfabeto ou semianalfabeto & - & 3 & - & 3 & 18,7 \\
\hline Curso Fundamental & 3 & 1 & 5 & 9 & 56,2 \\
\hline Curso Médio ou técnico & 2 & 1 & - & 3 & 18,7 \\
\hline Curso Superior & 1 & - & - & 1 & 6,2 \\
\hline Subtotal & 6 & 5 & 5 & 16 & 100 \\
\hline \multicolumn{6}{|l|}{ Religião } \\
\hline Católica & 6 & 5 & 3 & 14 & 87,5 \\
\hline Evangélica & - & - & 1 & 1 & 6,2 \\
\hline Sem religião & - & - & 1 & 1 & 6,2 \\
\hline Subtotal & 6 & 5 & 5 & 16 & 100 \\
\hline \multicolumn{6}{|l|}{ Local de residência } \\
\hline Meio rural & - & 2 & - & 2 & 12,5 \\
\hline Meio urbano & 6 & 3 & 5 & 14 & 87,5 \\
\hline Subtotal & 6 & 5 & 5 & 16 & 100 \\
\hline \multicolumn{6}{|l|}{ Local de ocorrência } \\
\hline Residência & 6 & 3 & 4 & 13 & 81,2 \\
\hline Rua & - & 1 & - & 1 & 6,2 \\
\hline Roçado & - & 1 & - & 1 & 6,2 \\
\hline Empresa & - & - & 1 & 1 & 6,2 \\
\hline Subtotal & 6 & 5 & 5 & 16 & 100 \\
\hline \multicolumn{6}{|l|}{ Método } \\
\hline Enforcamento & 2 & 2 & 3 & 7 & 43,7 \\
\hline Arma de fogo & 2 & 1 & 1 & 4 & 25 \\
\hline Envenenamento & - & 2 & 1 & 3 & 18,7 \\
\hline Queda & 1 & - & - & 1 & 6,2 \\
\hline Queimadura & 1 & - & - & 1 & 6,2 \\
\hline Subtotal & 6 & 5 & 5 & 16 & 100 \\
\hline \multicolumn{6}{|l|}{ Dia da semana da ocorrência } \\
\hline Segunda a sexta & 5 & 4 & 5 & 14 & 87,5 \\
\hline Finais de semana & 1 & 1 & - & 2 & 12,5 \\
\hline Subtotal & 6 & 5 & 5 & 16 & 100 \\
\hline \multicolumn{6}{|l|}{ Horário da ocorrência } \\
\hline Manhã & 2 & 4 & 2 & 8 & 50 \\
\hline Tarde & 3 & 1 & 2 & 6 & 37,5 \\
\hline Noite & 1 & - & 1 & 2 & 12,5 \\
\hline Subtotal & 6 & 5 & 5 & 16 & 100 \\
\hline
\end{tabular}

(2) Interface comunicação SAÚdE EDUCAÇÃo 
Entre os idosos que faleceram por suicídio, predominaram homens $(87,5 \%)$, casados $(68,5 \%)$, com educação formal Fundamental completa $(56,2 \%)$, pertencentes à religião católica $(87,5 \%)$ e residentes na área urbana $(87,5 \%)$. Identificaram-se idosos com vínculos matrimoniais desfeitos pelo divórcio ou separações (18,7\%); um percentual representativo de analfabetos ou analfabetos funcionais (18,7\%) e dos que concluíram o Ensino Médio (18,7\%).

No tocante às diferenças entre os sexos, a literatura ${ }^{5,8,22}$ aponta que mulheres atentam mais contra suas vidas, e os homens são mais assertivos quanto ao suicídio. Este estudo corrobora a literatura, uma vez que foi encontrada predominância masculina por meio dos dados epidemiológicos e dos casos registrados no Instituto Médico Legal. Quanto aos baixos níveis de escolaridade, a situação dos idosos coaduna-se com a da população do Nordeste. Meneghel et al. ${ }^{20}$ reforçam a ideia de que os idosos que faleceram por suicídio com melhores níveis foram identificados nas regiões Sul e Sudeste do País.

Quanto à questão religiosa, dados atuais do $\mathrm{IBGE}^{23}$ confirmam que, no Brasil, continua a predominar o catolicismo. Não se observou, no entanto, a influência da religião nos casos estudados, embora, do ponto de vista preventivo, Cassorla ${ }^{14}$ lembre que as crenças religiosas são um dos pilares de resistência para que pessoas em situação de sofrimento suportem com maior serenidade suas dificuldades e não cometam suicídio.

Uma questão importante observada no estudo dos idosos vítimas de suicídio no Nordeste é a migração do campo para a cidade. Várias dessas pessoas demonstravam sofrimento pela ruptura de laços sociais, pela perda da cultura e dos vínculos, pela dificuldade de se adaptar aos costumes da vida urbana, o que contribuía, entre outros fatores, para sua situação de vulnerabilidade 7,24 .

No grupo estudado, a maioria dos suicídios ocorreu nas próprias residências $(81,2 \%)$, com predomínio das mortes nos dias úteis $(87,5 \%)$, nos períodos da manhã $(50 \%)$ e tarde $(37,5 \%)$. Em seu estudo sociológico, Durkheim ${ }^{12}$ descobriu que a maior parte dos suicídios, nas regiões pesquisadas por ele, ocorreu durante o dia, no momento em que os negócios estavam mais ativos, as relações humanas se cruzavam e entrecruzavam, e a vida social estava mais intensa.

Os atos fatais praticados pelos idosos do Ceará e do Piauí foram por enforcamento (43,7\%), arma de fogo $(25 \%)$ e envenenamento $(18,7 \%)$. Esses dados acompanham a literatura nacional ${ }^{19,25} \mathrm{e}$ internacional26.

\section{Experiências que antecederam o suicídio do idoso}

Os idosos no contexto social e cultural, em determinadas fases de vida - como aposentadoria, impossibilidade de exercer a profissão por dependências físicas e psicológicas e surgimento de doenças crônicas - se deparam com mudanças negativas e perdas que, frequentemente, Ihes causam uma espécie de morte social e subjetiva. Esse sentimento se traduz em isolamento, angústia e dificuldades no relacionamento com seu grupo social. Isso fica muito evidente nas narrativas de vida ouvidas dos seus familiares, como se constata a seguir.

“Nos últimos dias, ele estava mais triste, ele estava trocando frases, palavras, às vezes ele trocava até o nome das filhas". (viúva, sobre homem casado, 61 anos, Fortaleza)

“[...] Às vezes, conversava de forma desconexa, esquecendo o que estava falando e mudava de assunto com freqüência". (sobrinha, sobre mulher solteira, 64 anos, Teresina)

Essas falas demonstram alterações no fluxo do pensamento, aumento da confusão mental e dificuldade de comunicação. Tal comportamento que, no decorrer da narrativa familiar, se provou que era acompanhado de profunda tristeza, não constitui uma característica da pessoa idosa. Ela é circunstancial e provocada por muitos fatores ${ }^{2,25,26}$. Na realidade, mesmo de forma desconexa, essa fala mostra que o idoso ainda estava ligado à vida, ainda que de forma confusa, o que lhe dificultava ser compreendido por quem o cercava; acredita-se que "o suicídio é um ato de desespero de quem não faz mais questão de viver"13. 
CIRCUNSTÂNCIAS QUE ENVOLVEM O SUICÍDIO ...

\begin{abstract}
"Ela chorava muito e não falava o que estava sentindo, só chorava e procurava ficar perto das pessoas". (sobrinha, sobre mulher solteira, 64 anos, Teresina)

"[...] ele vivia triste, isolado, era essa tal da depressão, sofria de insônia, demorava demais para dormir, aí vivia em casa, no canto dele". (irmã, sobre homem casado, 73 anos, Tauá)
\end{abstract}

Mais uma vez, estão presentes: a tristeza, a insuportabilidade do sofrimento, o isolamento, a falta de diálogo e a enunciação da depressão. Durkheim ${ }^{13}$ lembra que "o sistema mental de um povo é um sistema de forças definidas que não podem ser desordenadas nem reordenadas por meio de simples injunções. Ele está ligado à maneira pela qual os elementos sociais estão agrupados ou organizados" . Assim, esse isolamento do convívio social vem acompanhado, ao mesmo tempo, nos dois casos citados, pelo afrouxamento das referências identitárias, como se o idoso se sentisse um estranho no mundo, vivendo "em seu canto". A posteriori, em geral, os familiares se culpam e se arrependem de não terem sido mais atentos aos sinais dessa "morte social", mesmo dentro de uma família e cercado de gente g-14,16,21. $^{\text {. }}$

Essa perda de identidade e de sentido da vida, frequentemente passa despercebida das famílias. E ela está ligada a questões relativamente simples do cotidiano: privação de objetos individuais e particulares, troca de casa para morar com os filhos, abrindo mão do seu jeito de levar a vida em favor de outros adultos que passam a dominar a cena familiar, mudança de quartos confortáveis para outros menores e mais restritos (às vezes na própria casa), dando lugar à ocupação de seu antigo espaço pelos filhos casados, ou seja, com perda da autonomia relativa aos seus bens e pouco espaço no ambiente familiar para expressão de suas necessidades $5^{5,6,26-29}$.

"Acredito que ele já estava com depressão há muito tempo e o filho, mesmo trabalhando com ele, não percebia". (ex-esposa, sobre homem, divorciado, 72 anos, Teresina)

Como é possível observar, nesse depoimento, o isolamento social aqui se expressa ainda que no âmbito do convívio com outras pessoas: "o filho não percebia", embora lhe provesse as necessidades básicas de sobrevivência ${ }^{28}$. É assim em vários casos: o estado de depressão, que inicialmente aparece como sentimento de tristeza e isolamento, pode desencadear manifestações mais graves, tais como as percebidas pela ex-mulher. A pouca atenção, no entanto, que muitos familiares dedicam aos seus idosos - e essa atenção não pode ser interpretada como cuidado material apenas - é um fator desencadeador potente de pensamentos, tentativas e do suicídio. Assim, os familiares se deparam com o desafio de cuidar de maneira muito mais abrangente e específica e de propiciar, ao idoso, formas de apoio profissional, sobretudo quando estão em jogo estressores psicossociais e alterações psíquicas $^{24,27,28,30}$.

Falta de interesse e de alegria de viver, atitudes negativas, tristeza, distúrbios do sono ${ }^{5-7,10,11,26}$ são considerados as principais expressões da depressão. Com efeito, o idoso suicida depressivo já não tem apego à existência, porque seus laços subjetivos e sociais se encontram enfraquecidos e distanciados, portanto, da realidade subjetiva e social. Embora Durkheim ${ }^{13}$ tenha dado ênfase aos aspectos sociais envolvidos no suicídio, ele também ressaltou a importância do sentido da vida para o ser humano, "querendo ele mesmo determina seu próprio fim, arrasta mergulhado em desânimo e tédio, uma existência que lhe parece então desprovida de sentido".

É importante ressaltar que, dentre os transtornos mentais, a depressão é o que está mais fortemente relacionado ao suicídio. Aproximadamente 15\% das pessoas diagnosticadas com uma enfermidade depressiva se suicidaram no mundo no ano 2000, segundo a Organização Mundial de Saúde ${ }^{31}$. A depressão, assim como o suicídio, é determinada por fatores complexos de ordem psíquica, física, social e cultural e ambiental, que precisam ser levados em conta na Política Nacional de Saúde Mental ${ }^{9,11}$. Não se pode afirmar, no entanto, que todo depressivo é suicida, tampouco que todo idoso que morreu por suicídio seria depressivo. Estudo ${ }^{32}$ mostra uma relação entre falta de suporte social, ideias suicidas e sintomas de depressão. Considerando esses dois fatores - falta de suporte e ideação suicida - é importante que as propostas de prevenção sejam abrangentes e deem orientações gerais para a 
sociedade e específicas para os familiares e amigos, nos casos concretos. Desse modo, compreende-se que tais intervenções relativas a idosos com quadros de depressão devem comportar um trabalho de "repetição de suas histórias, por meio da qual eles produzam deslizamentos ou efeitos de deriva que possibilitem a emergência de novos dizeres sobre eles mesmos" 33 .

O fato de se observarem reflexos de depressão nas falas dos entrevistados não significa, necessariamente, que os idosos aqui estudados tivessem depressão severa; e as falas dos familiares não oferecem o diagnóstico incondicional de depressão. Para tanto, é importante associar outros tipos de fatores, como é o caso de doenças crônicas:

"Dias antes de cometer suicídio ele (idoso) se mostrou bastante abalado emocionalmente, em decorrência dos efeitos adversos consequentes do tratamento de câncer". (filha, sobre homem divorciado, 65 anos, Teresina)

As doenças crônicas fazem parte da realidade de muitos idosos e costumam provocar alterações emocionais. Na vivência desse tipo de enfermidade, o idoso passa de saudável e ativo à condição de doente, mesmo quando sua capacidade funcional não diminui. O confronto com tal situação, no entanto, frequentemente ocorre sem abertura para algum tipo de reorganização da vida e aceitação das novas limitações. No caso dos idosos, o impacto emocional é maior quando se soma a outros tipos de mudanças, como: saída do mundo do trabalho, afastamento dos companheiros de profissão, perda de entes queridos, deixando-o num não-lugar social.

Nos casos de doenças graves associadas ao suicídio, pesam muito, para os idosos, a convivência com dores físicas que se intensificam e problemas ligados ao desempenho sexual, que criam uma situação de insuportabilidade ${ }^{13,14,16}$. Nos relatos das famílias, o câncer surgiu como uma doença ameaçadora, com consequências para o estado mental do idoso e da família. Conforme Duarte e Rego ${ }^{1}$, a associação entre depressão e doenças crônicas pode ser vista de modo bidirecional: a depressão precipitando doenças crônicas e as doenças crônicas exacerbando sintomas depressivos.

\section{Enunciação do suicídio pelo idoso aos seus componentes familiares}

As relações familiares são aqui identificadas como os vínculos estabelecidos com os diversos membros da família, por possuírem ligações afetivas, independentemente de conviverem na mesma residência. Entendem-se por ligações afetivas o estabelecimento do vínculo, as relações estabelecidas com o outro, de modo a desencadear reações positivas ou negativas.

A comunicação estabelecida pela família é importante para a reconstituição da história dos dias que antecederam o suicídio e, também, como era a dinâmica familiar:

\footnotetext{
“Ele não desabafava nem pedia apoio sobre as brigas, exigências da sua esposa, nem mesmo sobre o problema de dívidas [que tinha contraído], assim as fronteiras entre as pessoas de dentro e fora da família eram delimitadas com rigidez". (irmã, sobre homem, casado, 73 anos, Teresina)
}

Neste discurso, o descontrole financeiro possibilitou os conflitos familiares; conflitos que não eram reconhecidos e, possivelmente, para os quais nem se procurava a resolução. Esse idoso tinha brigas constantes com a esposa por causa de dívidas, porque era incapaz de prover as necessidades financeiras da família. O homem sofria muito com isso, pois sua cultura machista lhe dizia que deveria ser capaz, até o fim da vida, de realizar tarefas de liderança, supremacia, e de desempenhar seu papel de provedor $^{19}$. Quando ocorreram falhas nessa função, ele se sentiu humilhado e não pediu ajuda.

Entre os homens, o fator cultural mais relevante associado ao suicídio é a perda de status que o trabalho ou emprego confere - criando uma sensação de ausência de lugar social ${ }^{29}$. O ocultamento do problema a quem poderia ajudar a solucioná-lo, barreira cultural que o impede de estabelecer uma comunicação sincera com as pessoas próximas, em geral, sufoca o homem machista em sofrimentos insuportáveis. 
CIRCUNSTÂNCIAS QUE ENVOLVEM O SUICÍDIO ...

Autopsia psicossocial realizada em Quebec, com 95 participantes, concluiu que, nos seis meses anteriores ao suicídio, a desordem familiar manifestada por perda de membros da família, separação ou conflitos com familiares ou amigos, e problemas financeiros foram fatores de risco significantes para o suicídio ${ }^{6}$. Outros estudos ${ }^{20,29}$ apontam que, quando o homem se encontra em grande dificuldade para realizar seu papel de provedor da família, em decorrência de crises econômicas, passa a considerar o suicídio a alternativa para resolver de vez seus fracassos.

Alguns idosos, ao longo de suas vidas, vivenciam perdas significativas, seja física, material, emocional e psicológica. Tais perdas representam um peso muito forte em suas vidas e precipitam a vontade de dar cabo à vida. O relato significativo de um familiar entrevistado aponta para essa situação:

\begin{abstract}
"Ela sempre se mostrou inconstante emocionalmente e deixava claro nunca ter se sentido feliz na vida. Os frequentes e intensos conflitos familiares vivenciados pela mesma contribuíram significativamente para o fortalecimento da ideação suicida. Um dos maiores potencializadores desse sofrimento, foi a perda do filho mais novo, tendo em vista que a mesma ocorreu precocemente e de forma traumática". (filho, sobre mulher separada, 68 anos, Teresina)
\end{abstract}

O caso citado diz respeito a uma idosa jovem que, com a perda do filho em um acidente, teve grande prejuízo em sua qualidade de vida. O intenso sofrimento a deixou em grande vulnerabilidade, e não ocultava dos familiares o fato de que era uma pessoa infeliz. Tal relato verbal poderia ser interpretado como um pedido de ajuda e uma forma de buscar apoio. A não-escuta dessa situação pode ter precipitado o ato suicida.

Mais uma vez, estão presentes: a tristeza, a insuportabilidade do sofrimento, o isolamento, a falta de diálogo e a enunciação da depressão. Durkheim lembra que

[...] o sistema mental de um povo é um sistema de forças definidas que não podem ser desordenadas nem reordenadas por meio de simples injunções. Ele está ligado à maneira pela qual os elementos sociais estão agrupados ou organizados..$^{13}$

A vida, diz-se, só é tolerável quando se percebe nela alguma razão de ser, quando ela tem um objetivo ${ }^{13,14,16}$. A falta de sentido interfere nas relações interpessoais e pode exacerbar conflitos intrafamiliares, como se pode observar na fala a seguir:

\footnotetext{
“Ele era muito sofrido, tinha uma aparência emagrecida e sempre relatava que não tinha sorte com as mulheres, a tristeza dele era que nenhum casamento tinha dado certo, ele brigava demais com a última esposa, ele ficava muito triste porque ela o desrespeitava, brigavam no meio da rua". (irmão, sobre homem, casado, 61 anos, Tauá)
}

No decorrer da sua vida, o citado idoso havia casado três vezes, e todos os casamentos desencadearam o mesmo desfecho: a separação. As buscas por explicações para a frustração matrimonial, todavia, diversificaram-se: do primeiro casamento, restou a traição da esposa, que tentou se matar e terminou grávida de outro homem; o segundo foi marcado por desgostos da esposa relacionados à desassistência do marido em centrar-se no trabalho. Mesmo assim, porém, viveu anos a fio um casamento de aparências; o terceiro foi caracterizado por intensas brigas, por vezes em público, o que causou muita vergonha ao homem.

Um problema bastante comum que se associa ao suicídio de homens idosos é a exacerbação do machismo humilhado, quando existem problemas com a sexualidade masculina ${ }^{29}$. Em sua socialização, o ato de perder o controle sobre seu matrimônio reporta-se à questão de honra e respeito. No relato feito há pouco, as situações conflituosas na relação ameaçavam o processo de identificação desse homem, motivando-Ihe sentimentos de tristeza e muito sofrimento. Assim, a perda do controle sobre as esposas ou companheiras, o que, na cultura patriarcal, representa falha no exercício do papel masculino, foi-lhe insuportável e precipitou o desfecho suicida ${ }^{13,29,34}$. 
Entre a diversidade de manifestações e verbalizações dos idosos, a enunciação do desejo de morrer é o primeiro que aflora. Em alguns idosos, a enunciação do suicídio ocorreu com suporte em intensas discussões familiares, cujos vínculos afetivos eram conflituosos, e, em outros, em situação de vulnerabilidade decorrente dos efeitos adversos consequentes de doenças crônicas, das próprias contingências do envelhecimento e da perda da identidade social, ou por motivos morais. As falas a seguir, retratam tais situações:

\begin{abstract}
“Meu avô chegou em casa bêbado e começou a discussão, não lembro o motivo, era sempre aquelas discussões. Ela [a mulher] reclamava da bebida, começava assim 'mas rapaz, tu já está bêbado? Então ele ameaçou que ia se matar, a vizinha ouviu a discussão, foi lá em casa e disse 'não se preocupa, quem quer se matar, não saí por aí dizendo' e levou minha avó para a casa dela. Com cinco minutos ela pediu para o neto ir ver o que ele [o avô] estava fazendo porque ele ficou sozinho em casa. Ao chegar lá, o neto encontrou o avô com uma corda no pescoço, morto". (neto, sobre homem, casado, 61 anos, Teresina)
\end{abstract}

Este caso acrescenta um elemento importante aos fatores de risco, que é o abuso de álcool. Estudo realizado com a população de Itabira ${ }^{25}$ apontou que o desencanto com as perspectivas de vida atuais e de projetos de vida e o uso abusivo de álcool são problemas que têm forte impacto na opção pelo suicídio. É bem verdade que esse abuso pode ser uma consequência, e não uma causa das insatisfações que, sobretudo, o homem passa a ter por não suportar determinados tipos de perdas e sofrimentos ou, mesmo, por não aceitar as contingências da velhice. A ruína do mundo interno retrata a fuga da realidade por meio do uso de bebida alcoólica, abalando as interações sociais e os vínculos afetivos, fragilizando o seu lugar no mundo.

Durkheim ${ }^{13}$ discorre sobre como a vida, com frequência, é difícil, muitas vezes decepcionante ou vazia. Esse vazio toma conta do indivíduo a ponto de depositar, na desesperança, o único sentido de morrer. Para compreender essas implicações, reporta-se ao fato de que a sociedade trata, ainda, o suicídio como "tabu", assunto que não pode ser discutido, devendo ser silenciado. O sentido atribuído a quem fala que quer morrer é o de não querer se matar, mas, simplesmente, despertar atenção dos familiares, amigos e sociedade. O sujeito que anuncia o desejo de praticar o suicídio encontra-se em total fragilidade - perde a força física, mental e crítica, e a condição de reagir diante dos fracassos precisa ser levada a sério.

Como bem sinalizado no documento destinado a profissionais da saúde em atenção primária sobre prevenção do suicídio ${ }^{30}$, quando o idoso narra a sua descrença pela vida e ausência de motivos para continuar a viver, ele quer ser ouvido efetivamente para recuperar a esperança de que os fracassos e fragilidades podem ser superados. As narrativas rejeitadas ou convenientemente não ouvidas pelos familiares e amigos, frequentemente, mostram que o sentido da vida foi dominado pelo senso da morte, como provam os casos a seguir:

“Ele havia ingerido álcool e estava muito zangado, estava consciente e decidido a cometer o suicídio, inclusive na hora do acontecido, avisou à mulher e a filha, chamando-as para assistirem, ao que foi desafiado pela esposa, que dizia que ele não tinha coragem por ser fraco". (irmã, sobre homem, casado, 73 anos, Teresina)

\footnotetext{
“Ele estava com um semblante mudado, quando foi de manhã, se levantou, me abraçou, aí falou 'foi a última vez que dormi nessa casa', aquilo era uma coisa que ele sempre falava, fiquei calada e ele disse 'porque de hoje eu não passo, não'". (viúva, sobre homem, casado, 68 anos, Tauá)
}

Esses relatos mostram a ideia, muito corrente entre as famílias, de que o idoso não cometeria suicídio. Primeiro, o idoso sob o efeito do álcool, além de anunciar verbalmente a vontade de se matar, convida a filha e a esposa para assistirem ao ato fatal. Quando se confrontam os maiores temores na vida, desencadeam-se reações psíquicas e emocionais diversas. Quando possuído pela raiva, o idoso, 
CIRCUNSTÂNCIAS QUE ENVOLVEM O SUICÍDIO ...

atormentado pela impossibilidade de se adaptar às mudanças ocorridas em sua vida, encontra-se diante da fatalidade da morte. Ao chamar familiares para visualizarem o ato suicida, o idoso demonstrou a severidade da desesperança em que se encontrava diante das contradições da sua vida, incluindo a relação com sua esposa e a sua filha.

O outro caso também revela a vontade do idoso de antecipar o fim da sua vida. Os dois são similares no que diz respeito às reações dos familiares diante da anunciação do suicídio. Numa situação, além da descrença do ato suicida, houve o desafio; na outra, aconteceu o silêncio. Em nenhum dos casos, o idoso foi ouvido efetivamente. E, neste sentido, pode-se entender que o sentimento de desesperança foi internalizado de forma tão intensa que culminou em desespero, na morte autoinflingida.

\section{Considerações finais}

As falas dos familiares elucidaram que existe sim, por parte do idoso, o desejo de antecipar seu fim, e isso pode ser confirmado com a enunciação verbal do suicídio. Ressalta-se, portanto, a importância de se dissociar a ideia do senso comum de que as pessoas que almejam o fim da sua vida não manifestam pistas verbais, pois elas falam de suas desesperanças, de busca intensa pelo fim do seu sofrimento, e tais enunciações não podem ser ocultadas, precisam ser compreendidas e explicitadas para que encontrem ajuda necessária.

É inegável o fato de que o suicídio traz consequências substanciais para as famílias e a sociedade. Desse modo, compreende-se ser necessário ultrapassar a barreira da discussão do campo teórico e do discurso posterior dos diversos agentes sociais - familiares, amigos e profissionais da saúde - de que poderiam "ter feito mais". Primeiramente, nunca se pode esquecer de que o suicídio é um ato voluntário. Também é preciso ter consciência, entretanto, de que ele ocorre ante a insuportabilidade do sofrimento. Isso significa que o suporte mútuo - como a mão estendida que se solidariza e o ouvir atento que busca compreender os sentimentos geralmente recalcados nos corações dos idosos - muito pode ajudar.

Além disso, existe muito pouco investimento na preparação da aposentadoria que, geralmente, para muitos idosos, significa perda do papel e do lugar social. Nesta realidade, surgem as dificuldades financeiras, o aparecimento ou agravamento de doenças crônicas, os conflitos familiares em torno do uso abusivo do álcool, e o cotidiano se deteriora pelas alterações no humor, isolamento social e manifestações depressivas.

Este estudo, como parte de uma pesquisa mais complexa, aponta para um caminho árduo com vistas a identificar e compreender o idoso sob risco de suicídio. Os casos dos idosos que faleceram por suicídio no Nordeste brasileiro dizem respeito à cultura do fechar-se em si mesmo, do isolamento humano e da tensão do sentido de viver. Assim, o conhecimento constituído poderá oferecer subsídios para elaboração de estratégias de prevenção, sobretudo, para a atenção básica.

É reconhecido o fato de que o idoso pode estar vulnerável ao surgimento de crises existenciais, sobretudo às relacionadas aos marcadores identitários em que podem ocorrer transtornos mentais, sendo os mais comuns, as mudanças de humor e depressão. Essa é uma situação muitas vezes possível de ser evitada, mas não está tratada de modo suficiente pela Política Nacional de Saúde Mental32. Apenas excepcionalmente os centros de atenção psicossocial (CAPS) estão preparados para realizar uma atenção específica que leve em conta as particularidades dos sofrimentos dos idosos. 


\section{Colaboradores}

Girliani Silva de Sousa, Raimunda Magalhães da Silva e Luiza Jane Eyre de Souza Vieira trabalharam na concepção do projeto, coleta de dados, interpretação dos dados e redação do artigo. Ana Elisa Bastos Figueiredo e Maria Cecília de Souza Minayo participaram na revisão crítica e redação final do texto.

\section{Referências}

1. Duarte $M B$, Rego MA. Comorbidade entre depressão e doenças clínicas em um ambulatório de geriatria. Cad Saude Publica. 2007; 23(3):691-700.

2. Veras R. Envelhecimento populacional contemporâneo: demandas, desafios e inovações. Rev Saude Publica. 2009; 43(3):548-54.

3. Veras R. Em busca de uma assistência adequada à saúde do idoso: revisão de literatura. Cad Saude Publica. 2003; 19(3):705-15.

4. World Health Organization. Active ageing: a policy framework. Genebra: WHO; 2002.

5. Préville $M$, Hébert R, Boyer R, Bravo G, Seguin M. Physical health and mental disorder in elderly suicide: a case-control study. Agin Mental Health. 2005; 9(6):576-84

6. Beautrais AL. A case-control study of suicide and attempted suicide in older adults. Suicide Life Threat Behav. 2002; 32(3):1-9.

7. Conwell $Y$, Duberstein PR, Caine ED. Risk factors for suicide in later life. Biol Psychiatry. 2002; 52(3):193-204.

8. Minayo MCS, Cavalcante FG. Suicídio entre pessoas idosas: revisão da literatura. Rev Saude Publica. 2010; 44(4):750-57

9. De Leo D, Padoani W, Scocco P, Bille-Grahe U, Arcsnman E, Bjerke T et al. Elderly suicidal behaviour: results from WHO/EURO Multicentre Study on Parasuicide. Int J Geriatr. Psychiatr. 2001; 16(3):300-10.

10. Werneck GL, Hasselmann MH, Phebo LB, Vieira DE, Gomes VLO. Tentativas de suicídio em um hospital geral no Rio de Janeiro, Brasil. Cad Saude Publica. 2006; 22(10):2201-6.

11. Bernardes SS, Turini CC, Matsuo T. Perfil das tentativas de suicídio por sobredose de medicamentos atendidas por um Centro de Controle de Intoxicações do Paraná, Brasil. Cad Saude Publica. 2010; 26(7):1366-272.

12. Figueiredo AEB, Silva RM, Mangas RMN, Vieira LJS, Furtado HMJ, Gutierrez DMD, et al. Suicídio de idosos: impactos na família brasileira. Cienc Saude Colet. 2012; 17(8):1993-2002.

13. Durkheim E. O suicídio: um estudo sociológico. Rio de Janeiro: Zahar; 2011.

14. Cavalcante FG, Minayo MCS. Autópsias psicológicas e psicossociais de idosos que morreram por suicídio no Brasil. Cienc Saude Colet. 2012; 17(8):1943-54.

15. Cassorla RMS. O que é suicídio. 5a ed. São Paulo: Brasiliense; 2005.

16. Shneidman ES. Autopsy of a suicidal mind. Oxford: Oxford University Press; 2004.

17. Pinto LW, Assis SG, Pires TO. Mortalidade por suicídio em pessoas com 60 anos ou mais nos municípios brasileiros no período de 1996 a 2007. Cienc Saude Colet. 2012; 17(8):1963-72.

18. Pinto LW, Assis SG, Silva CMFP, Pires TO. Evolução temporal da mortalidade por suicídio em pessoas com 60 anos ou mais nos estados brasileiros, 1980 a 2009. Cienc Saude Colet. 2012; 17(8):1973-81. 
CIRCUNSTÂNCIAS QUE ENVOLVEM O SUICÍDIO ...

19. Pinto LW, Silva CMFP, Pires TO, Assis SG. Fatores associados com a mortalidade por suicídio de idosos nos municípios brasileiros no período de 2005-2007. Cienc Saude Colet. 2012; 17(8):2003-9.

20. Meneghel SN, Gutierrez DMD, Silva RM, Grubits S, Hesler LZ, Ceccon RG. Suicídio de idosos sob a perspectiva de gênero. Cienc Saude Colet. 2012; 17(8):1983-92.

21. Cavalcante FG, Minayo MCS, Meneghel SN, Silva RM, Gutierrez DMD, Conte M, et al. Autópsia psicológica e psicossocial sobre suicídio de idosos: abordagem metodológica. Cienc Saude Colet. 2012; 17(8):2039-52.

22. Duberstein PR, Conwell Y, Conner KR, Eberly S, Caine ED. Suicide at 50 years of age and older: perceived physical illness, family discord and financial strain. Psychol Med. 2004; 34(1):137-46.

23. Instituto Brasileiro de Geografia e Estatística. Censo 2010 [acesso 2012 Out 9]. Disponível em: www.censo2010.ibge.gov.br

24. Muramato MT, Mângia EF. A sustentabilidade da vida cotidiana: um estudo das redes sociais de usuários de serviço de saúde mental no município de Santo André (SP, Brasil). Cienc Saude Colet. 2011; 16(4):2165-77.

25. Souza ER, Minayo MCS, Cavalcante FG. O impacto do suicídio sobre a morbimortalidade da população de Itabira. Cienc Saude Colet. 2007; 11 Supl:1333-42.

26. Barrero SAP. Factores de riesgo suicida en el anciano. Cienc. Saude Colet. 2012; 17(8):2011-6

27. Botega NJ, Werlang BSG, Cais CFS, Macedo MMK. Prevenção do comportamento suicida. Psico (Porto Alegre). 2006; 37(3):213-20.

28. Marques AKMC, Landim FLP, Collares PM, Mesquita RB. Apoio social na experiência do familiar cuidador. Cienc Saude Colet. 2011; 16 Supl. 1:945-55.

29. Heisel MJ, Conwell Y, Pisani AR, Duberstein PR. Concordance of self and proxy reported suicide ideation in depressed adults 50 years of age or older. Can J Psychiatry. 2011; 56(4):219-26.

30. Organização Mundial de Saúde. Prevenção do suicídio: um manual para profissionais da saúde em atenção primária. Genebra: OMS; 2000.

31. Organização Mundial de Saúde. Relatório mundial sobre violência e saúde: sumário. Geneve: OMS; 2002.

32. Ministério da Saúde. Política Nacional de Saúde Mental. Brasília, DF: MS; 2009.

33. Aleixo MRA, Figueiredo AEB. Envelhecimento, identidade e memória. Arq. Bras Psiquiatr Neurol Med Legal. 2005; 99(4):30-5

34. Minayo MCS, Meneghel SN, Cavalcante FG. Suicídio de homens idosos no Brasil. Cienc Saude Colet. 2012; 17(10):2665-74. 
Sousa GS, Silva, RM, Figueiredo AEB, Minayo MCS, Vieira LJES. Circunstancias que envolvieron el suicidio de ancianos. Interface (Botucatu).

El texto analiza experiencias y relaciones familiares que precedieron el suicidio de ancianos. Se trata de un estudio cualitativo, con método de autopsia psicosocial. Incluye 16 casos de ancianos que se suicidaron entre 2006 y 2009 en tres municipios del Nordeste Brasileño. A la luz del análisis de contenido se estudiaron las categorías: experiencias que precedieron el suicidio de ancianos y enunciación del suicidio por parte del anciano a sus familiares. Se destacan tres factores asociados al suicidio: alteraciones de humor y expresiones de estados depresivos, conflictos familiares juntamente con dificultades financieras y uso abusivo de alcohol e ideas suicidas por anunciación del deseo de anticipar el fin. Es necesaria la mirada amplia y la escucha reflexiva sobre el anciano por parte de los agentes sociales, familiares, amigos y diversos sectores, específicamente el sector de la salud, gestores y profesionales que causen cambios significativos en la dinámica del servicio.

Palabras clave: Anciano. Suicidio. Dinámica familiar. 
